\title{
Giant symptomatic rectal lipoma resected by endoscopic submucosal dissection
}

Gastrointestinal lipomas are benign, slow-growing tumors that are typically diagnosed incidentally during endoscopy $[1,2]$. They are more commonly located in the right colon; rectal involvement is uncommon [2-5]. Lipomas are characteristically asymptomatic but depending on their location and size [1], they can cause symptoms such as bleeding, obstruction, intussusception or prolapse $[1,2,4]$. Only three cases of rectal lipomas presenting with prolapse have been reported in the literature, and they are usually treated surgically.

We present the case of a 65-year-old woman who was referred to the Gastroenterology Department because of symptomatic intermittent rectal prolapse. The patient reported the need to manually reinsert the prolapse. Colonoscopy revealed a large subepithelial lesion in the distal rectum, adjacent to the upper margin of the anal canal ( $\mathbf{F i g} \mathbf{1}$ ). Axial contrast-enhanced pelvic computed tomography scan suggested a lipomatous lesion in the rectum. An echoendoscopy, using a dedicated anal probe $(7.5 \mathrm{MHz})$, revealed a well-demarcated, hyperechogenic, homogeneous lesion in the submucosa ( $\mathbf{F i g . 2}$ ), suggesting a lipoma [5]. The patient was proposed for endoscopic resection.

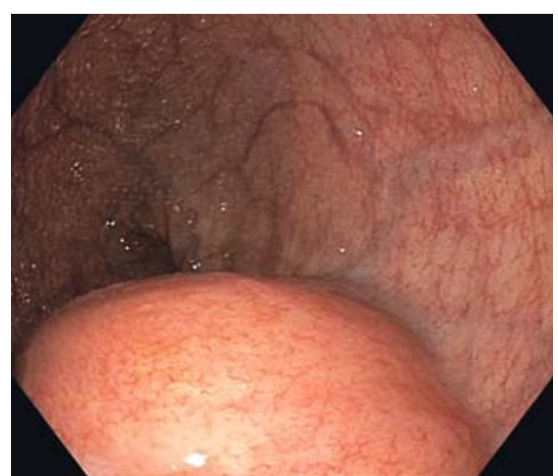

-Fig. 1 Endoscopic view of a large subepithelial lesion in the distal rectum.

The lesion was enucleated through endoscopic submucosal dissection (ESD) (> Fig.3, > Video 1). The dissection was performed, using an insulated-tipped knife 2 (KD-611L; Olympus, Tokyo, Japan), with the patient under deep sedation. There were no adverse events related to the procedure. The specimen was removed en bloc and was $60 \times 45 \mathrm{~mm}$ in size ( $\triangleright$ Fig.4). Pathological evaluation of the specimen confirmed it to be a benign submucosal lipoma. At follow-up, 18 months after ESD, the patient was asymptomatic.

To the best of our knowledge, this clinical case represents the third largest sympto-

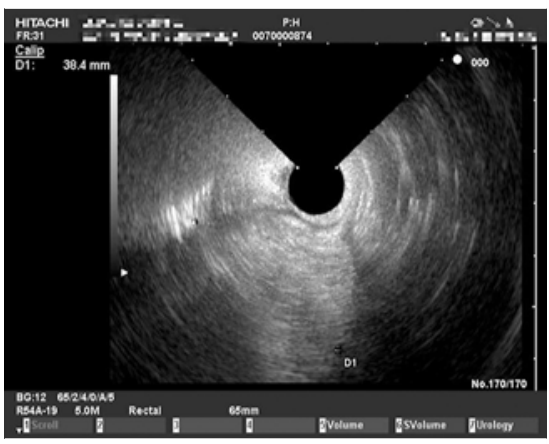

- Fig. 2 Echoendoscopy revealed a hyperechoic homogeneous lesion arising from the submucosa.

matic rectal lipoma reported in the literature [2,3], and the first to be treated by ESD. The development and implementation of ESD in the Western world allows patients with large subepithelial gastrointestinal lesions (especially below the muscularis propria), to be safely treated by endoscopy in experienced centers.

Endoscopy_UCTN_Code_TTT_1AS_2AZ

\section{Competing interests}

None
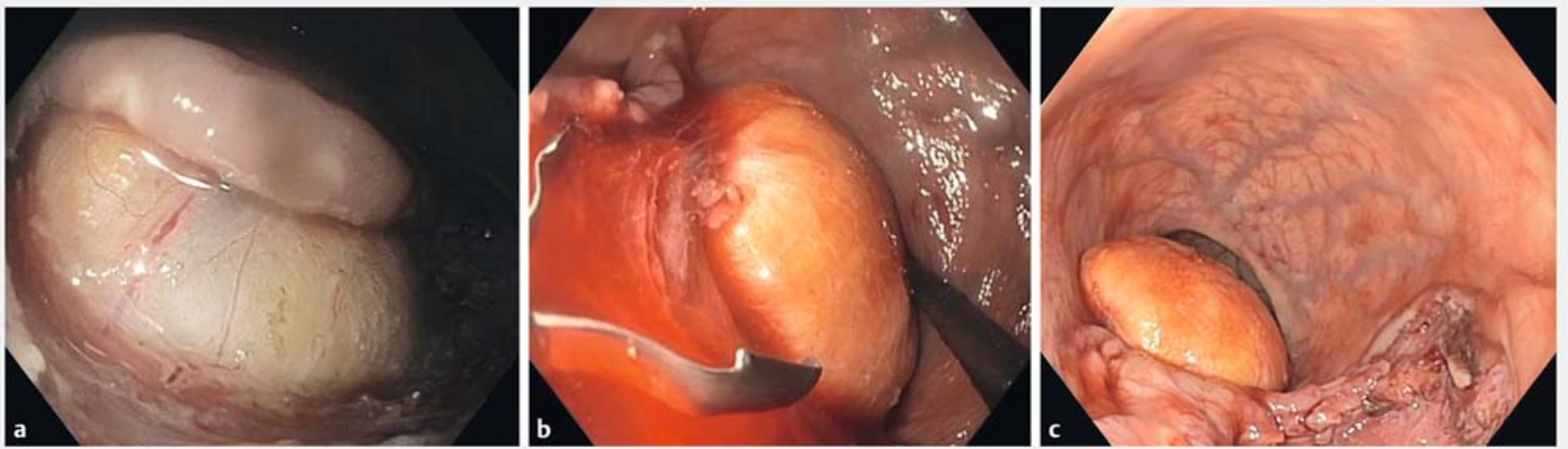

Fig. 3 Endoscopic submucosal dissection (ESD) of the lipoma. a Endoscopic view of the lipoma. $\mathbf{b}$ Ligation of the vascular pedicle with a hemostatic clip; forward traction using forceps. c Endoscopic view of the lesion and the mucosal defect after ESD. 

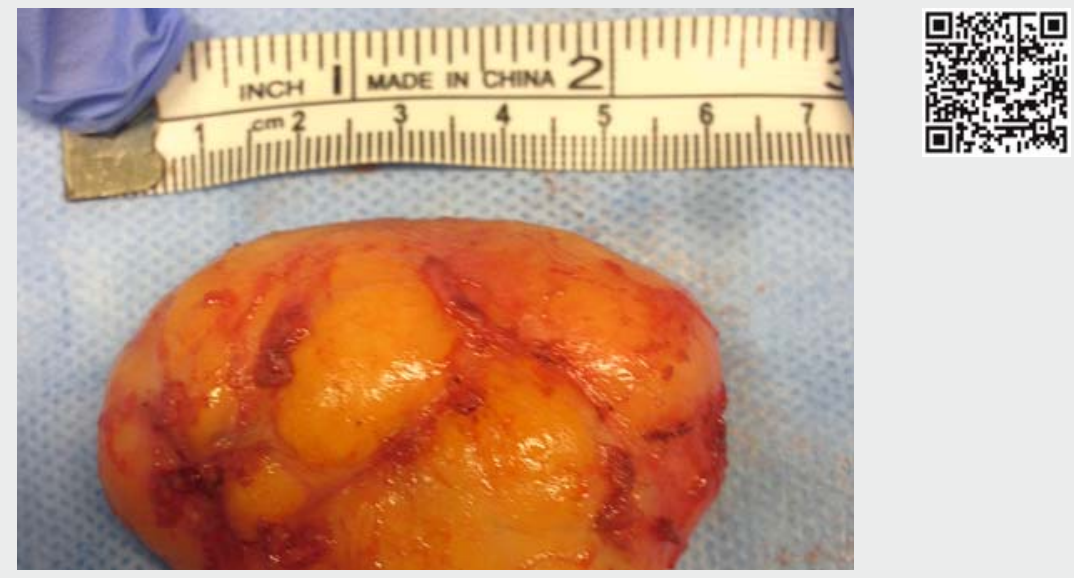

Video 1 Endoscopic submucosal dissection was used to resect a giant rectal lipoma that was causing prolapse of the rectal mucosa.

The authors

\section{João Fernandes ${ }^{1,2}$, Diogo Libânio ${ }^{3}$, Sílvia} Giestas ${ }^{1}$, Tarcísio Araújo ${ }^{1}$, David MartinezAres $^{1}$, Manuela Certo ${ }^{4}$, Luís Lopes ${ }^{1,5,6}$

1 Gastroenterology Department, Hospital Santa Luzia, Viana do Castelo, Portugal

2 Gastroenterology Department, Centro Hospitalar Cova da Beira EPE, Covilhã, Portugal

3 Gastroenterology Department, Instituto Português de Oncologia do Porto Francisco Gentil, Porto, Portugal

4 Radiology Department, Centro Hospitalar do Porto, Porto, Portugal

5 Life and Health Sciences Research Institute (ICVS), School of Medicine, University of Minho, Braga, Portugal

6 ICVS/3B's - PT Government Associate Laboratory, Braga/Guimarães, Portugal

Corresponding author

\section{João Fernandes, MD}

Department of Gastroenterology, Hospital de Santa Luzia, Unidade Local de Saúde do Alto Minho, Estrada de Santa Luzia, 4901858, Viana do Castelo, Portugal Fax: +351-275-751057

Jotillfernandes@hotmail.com

\section{Acknowledgment}

The authors gratefully acknowledge the generous assistance of all of the endoscopy unit staff.

\section{References}

[1] Lee KJ, Kim GH, Park DY et al. Endoscopic resection of gastrointestinal lipomas: a single-center experience. Surg Endosc Other Interv Tech 2014; 28: 185-192

[2] Arora R, Kumar A, Bansal V. Giant rectal lipoma. Abdom Imaging 2011; 36: 545 - 547

[3] Martellucci ], Civitelli S, Tanzini G et al. Transanal resection of rectal lipoma mimicking rectal prolapse: description of a case and review of the literature. ISRN Surg 2011; 2011: 170285

[4] Robert PE, Meurette G, Lehur PA. An unusual case of rectal prolapse. J Visc Surg 2011; 148: e452 - e453

[5] Kose E, Cipe G, Demirgan S et al. Giant colonic lipoma with prolapse through the rectum treated by external local excision: a case report. Oncol Lett 2014; 8: 1377-1379

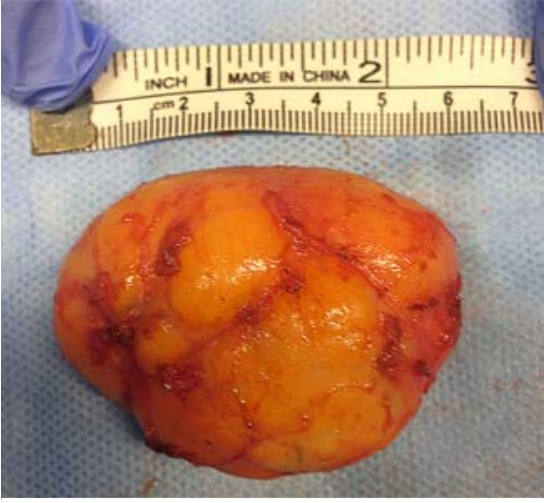

Fig. 4 The resected specimen, $60 \times 45 \mathrm{~mm}$ in size.

\section{Bibliography}

DOI https://doi.org/10.1055/s-0043-123876

Published online: 21.12.2017

Endoscopy 2018; 50: E63-E64

(c) Georg Thieme Verlag KG

Stuttgart $\cdot$ New York

ISSN 0013-726X

\section{ENDOSCOPY E-VIDEOS \\ https://eref.thieme.de/e-videos}

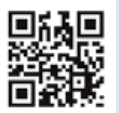

Endoscopy E-Videos is a free access online section, reporting on interesting cases and new techniques in gastroenterological endoscopy. All papers include a high quality video and all contributions are freely accessible online.

This section has its own submission website at https://mc.manuscriptcentral.com/e-videos 